\title{
Caloric Restriction to Moderate Senescence: Mechanisms and Clinical Utility
}

\author{
S. D. Anton • C. Karabetian • K. Heekin • \\ C. Leeuwenburgh
}

Published online: 17 October 2013

(C) Springer Science+Business Media New York 2013

\begin{abstract}
As life expectancy in the United States continues to increase, the maintenance of independence among older Americans has emerged as a major clinical and public health priority. Therefore, there is an urgent need to identify interventions that can maintain or enhance cognitive and physical function with the goal of preventing or delaying the onset of disability. To date, caloric restriction (CR) is the only method that has been consistently found to increase life span and delay the onset of age-associated diseases such as cancer and diabetes across multiple species. The promise of calorie restriction as an intervention to improve health and/or maintain function in humans, however, only holds if individuals are able to adhere to this intervention over the long term. Unfortunately, long-term adherence to $\mathrm{CR}$ regimens is notoriously poor, likely due to complex interactions between behavioral, physiological, psychological, and environmental variables. Thus, a current
\end{abstract}

\author{
S. D. Anton · K. Heekin · C. Leeuwenburgh \\ Department of Aging and Geriatric Research, Institute on Aging, \\ University of Florida, 2004 E. Mowry Road, Gainesville, FL 32610 , \\ USA \\ K. Heekin \\ e-mail: kaceydheekin@ufl.edu \\ C. Leeuwenburgh \\ e-mail: cleeuwen@ufl.edu \\ C. Karabetian \\ Department of Clinical and Health Psychology, College of Public \\ Health and Health Professions, University of Florida, Gainesville, \\ FL 32610, USA \\ e-mail: ckarabetian@ufl.edu \\ S. D. Anton $(\bowtie)$ \\ Department of Aging and Geriatric Research, Department of Clinical \\ and Health Psychology, College of Public Health and Health \\ Professions, College of Medicine, University of Florida, Gainesville, \\ FL 32611, USA \\ e-mail: santon@ufl.edu
}

challenge for both researchers and clinicians is to identify methods that can assist individuals in maintaining CR over the long term.

Keywords Caloric restriction · Aging · Adherence . Lifestyle $\cdot$ Health-span $\cdot$ Life span $\cdot$ Body weight $\cdot$ Appetite

\section{Introduction}

Aging is associated with a host of biological changes that contribute to a progressive decline in cognitive and physical function, ultimately leading to a loss of independence and increased risk of mortality. A number of factors have been associated with the pathogenesis of functional decline during aging and physical disability (in non-acute disease conditions), but the exact mechanisms contributing to this process remain largely undefined. As life expectancy in the United States continues to increase, the maintenance of physical independence among older Americans has emerged as a major clinical and public health priority [1]. Therefore, there is an urgent need to identify interventions that can maintain or enhance cognitive and physical function with the goal of preventing or delaying the onset of disability [2].

To date, caloric restriction (CR) is the only method that has been consistently found to increase life span and delay the onset of age-associated diseases such as cancer and diabetes across multiple species, including non-human primates [3]. Findings from animal studies suggest prolonged $\mathrm{CR}$ has the potential to extend health-span, the period of life when an individual is functional and free of serious illness, and potentially life span [4]. The precise mechanism through which CR exerts these beneficial effects is not known; however, findings from basic science indicate that $\mathrm{CR}$ produces broad systemic effects that can directly influence health and functional ability and thereby extend health-span. The beneficial effects of CR appear to be 
conserved across various animal species [5], and short-term studies demonstrate that the basic physiology of caloric restriction is well conserved in humans [6]. Moreover, findings from initial short-term randomized clinical trials support the promise of CR to improve health and potentially extend health-span and longevity in humans. Thus, there is hope that the beneficial effects of CR in delaying the onset of age-related disease conditions observed in various non-human species, including nonhuman primates, can be translated to humans.

The promise of $\mathrm{CR}$ as an intervention to improve health and/or improve function in humans, however, only holds if individuals are able to adhere to this intervention over the long-term. A concern associated with calorie-restricted diets is that they do not lead to lasting weight loss or health benefits and may lead to loss of fat-free mass and adverse changes in body composition over time [7]. Therefore, a current challenge is finding ways to minimize the loss of fat-free mass that typically occurs following $\mathrm{CR}$, while assisting individuals in maintaining CR over the long-term. In the sections below, we review the following: (1) definition of $\mathrm{CR}$, (2) basic mechanisms and physiological factors through which CR may exert its beneficial effects, (3) findings from animal and non-human primate studies, (4) findings from initial clinical trials in humans, (5) translation of CR to non-overweight individuals, (6) long-term utility of CR, (7) strategies to enhance adherence to $\mathrm{CR}$, and (8) alternative dietary approaches that may produce similar benefits of CR.

\section{Definition of Caloric Restriction}

Currently, there is no precise or universally agreed upon definition of CR. Some researchers have suggested that CR should be defined as a reduction in calories of approximately $30 \%$ from eating freely until satiation [8]. More recently, experts have suggested that the beneficial effects of CR begin at approximately $25-30 \%$ reduction from free living food intake and remain present up to a 50-65\% reduction in food intake [9]. These recommendations are based on initial studies in rodents that demonstrated that mice fed 55-65\% calorierestricted diets through their life exhibited a $35-65 \%$ greater mean and maximal life span compared to mice eating a nonpurified, ad libitum diet [10]. Notably, reductions in food intake greater than this amount for prolonged periods lead to a host of negative effects [11], as it is likely CR transitions into starvation at this point.

A limitation of many pre-clinical studies that have examined the effects of $\mathrm{CR}$ is that the animals in the comparison group are typically fed an ad libitum diet, which is known to lead to excessive food consumption and weight gain. Thus, the dietary intake of the animals in the ad libitum group would not be reflective of a "healthy" eating pattern. Additionally, animals are frequently confined within a limited space, which is likely to reduce physical activity levels. This combination of environmental factors (i.e., readily available food and limited space for movement) may contribute to unhealthy weight gain and ultimately increase risk of disease conditions that are known to be associated with obesity and sedentary lifestyle. A more strict comparison group would be one in which food is provided at a level sufficient to maintain a healthy body weight and produce weight stability. Fortunately, this type of comparison group has been used in recent randomized controlled trials testing the effects of $\mathrm{CR}$ in overweight humans. The findings of these trials are described below, following a brief discussion of the basic mechanisms through which CR exerts its effects and description of findings from animal models.

\section{Basic Mechanisms}

The beneficial effects of CR during aging are thought to be due, in large part, to its powerful anti-oxidative action [5] and ability to maintain a proper cellular redox status, as evidenced by suppressed oxidative damage to lipids, DNA, and proteins $[12,13 \cdot]$. Oxidative damage appears to be closely linked with systemic inflammation, and recent research suggests chronic molecular inflammation is a major biological mechanism underpinning the aging process and age-related diseases [5]. Recent evidence has documented the anti-inflammatory action of $\mathrm{CR}$, as shown by its modulation of pro-inflammatory genes (e.g., TNF- $\alpha$, IL-1, IL-6) and adhesion molecules (e.g., VCAM-1, E-selectin) through the NF- $\mathrm{kB}$ signaling pathway [5].

In addition to promoting proper redox status and antiinflammatory action, CR may confer significant health benefits through additional biological processes that can enhance cellular quality control including autophagy (i.e., "self-eating" of damaged organelles), activation of the ubiquitinproteosome system (UPS), which removes damaged proteins, and maintenance of a healthy population of mitochondria through biogenesis (i.e., generation of new mitochondria) $[14 \cdot, 15]$. Autophagy is an evolutionarily conserved process that allows eukaryotic cells to degrade and recycle long-lived proteins and organelles [16]. The decline in autophagic and proteasomal activity observed during aging has been proposed to contribute to different aspects of age-related phenotypes, such as neurodegeneration, osteoarthritis, and declining liver and T-cell function, as well as age-related muscle loss [17, 18]. Caloric restriction increases the activity and effectiveness of autophagy and the UPS [19,20]. Additionally, CR can support a healthy population of mitochondria through increasing mitochondria biogenesis $[15,21]$, as well as oppose the reductions in mitochondrial function that occur during aging by affecting the expression of genes such as PGC-1 $\alpha$ [22].

Findings from Animal and Non-Human Primate Studies

The measurement of the effect of CR on longevity parameters has been studied across a variety of species over the past century 
$[4,23,24,25 \bullet, 26]$. Caloric restriction has now been shown to increase longevity in a variety of species including rats [26], mice [27], yeast [28-32], flies [33-35], water fleas [36], nematodes [37-40], rotifers [41, 42], spiders [43], fish [44], hamsters [45], and dogs [46, 47]. The range of life span extension is typically between $30-60 \%$ in rodents $[4,27]$ but can vary significantly across species. In addition to extending life span, prolonged $\mathrm{CR}$ in rodents has also been found to delay the onset of age-associated disease conditions such as cancer and diabetes [26, 48]. Overall, findings from animal studies suggest prolonged CR has the potential to extend both health-span and life span, and improve quality of life during extended years.

In comparison to studies in short-lived species, the study of the effects of CR on health and aging parameters in non-human primates is relatively novel. Two main agencies have been involved in this line of research, the National Institute on Aging (NIA) and the Wisconsin National Primate Research Center (WNPRC), with studies focused on the effects of CR $\leq 30 \%$ in rhesus monkeys. Since 1987, the NIA study has been examining male and female monkeys introduced to $\mathrm{CR}$ at different stages throughout their life span. Monkeys in the control group were kept on a highly nutritious diet based on recommended caloric intake for age and body weight, whereas monkeys in the CR group received $30 \%$ calories from the same diet, also adjusted for age and body weight. All monkeys were given two meals per day [49]. In 1989, the WNPRC began to study both male and female monkeys that were introduced to $30 \% \mathrm{CR}$ as adults [49].

Findings related to mortality and morbidity are not conclusive at present, but initial findings from the WNPRC study indicate that moderate $\mathrm{CR}$ is effective in lowering the incidence of aging-related deaths in adult rhesus monkeys [3]. At the time of the data analysis for this publication, the majority of the CR monkeys had survived compared to only half (50\%) of control fed monkeys. Later findings by Mattison and colleagues (2012) indicate that the CR regimen implemented in rhesus monkeys at the NIA did not improve survival outcomes [50•]. These findings suggest the effects of CR on markers of health, which were consistently found in both the NIA and WNPRC studies, may not translate to reductions in morbidity and mortality. Consequently, additional evidence is needed to better understand the effects of CR on mortality and morbidity in non-human primates.

Preliminary and interim data analyses in both the NIA and WNPRC studies indicate that CR has a number of positive effects on a wide variety of health parameters including body weight, glucoregulatory function, cardiovascular and diabetes risk, muscle loss, incidence of neoplasia, bone health, and brain morphology [3, 49, 51, 52]. For example, the postmaturational decline in dehydroepiandrosterone (DHEAS) was significantly attenuated in adult CR monkeys compared to controls after three to six years of CR [53]. Additionally, melatonin levels in old CR monkeys (20-35 years old) were significantly greater than those observed in age-matched controls [54]. In the NIA study, pentosidine and furosine (i.e., two glycation products known to increase with age) showed positive correlations with age in control monkeys but not CR monkeys [49].

\section{Translation to Humans}

The effect of CR in humans has been examined in randomized controlled trials; however, results are limited to overweight adults. The Comprehensive Assessment of Long-Term Effects of Reducing Intake of Energy (CALERIE) was a multicenter study testing the hypothesis that CR improves biomarkers of longevity [55]. During Phase 1, independent studies were conducted at three different sites: Pennington Biomedical Research Center, Jean Mayer USDA Human Nutrition Research Center on Aging (HNRCA) at Tufts University, and the Washington University School of Medicine. An important goal of Phase 1 was to provide critical reference data to inform about appropriate study design for use in the longer-term trial during Phase 2.

At the Pennington Biomedical Research Center, overweight $\left(25 \leq\right.$ Body Mass Index $\left.[\mathrm{BMI}]<30 \mathrm{~kg} / \mathrm{m}^{2}\right)$ but otherwise healthy adults (25-50 years old) participated in 24 weeks of CR. Participants were randomized to one of four groups: (1) Healthy Weight Control; energy intake matched to energy requirements; (2) CR; $25 \%$ diet restriction; (3) CR plus exercise group (CREX); $12.5 \%$ CR plus a $12.5 \%$ increase in energy expenditure; and (4) low calorie diet group (LCD); $890 \mathrm{kcal} / \mathrm{d}$ diet until they reached $15 \%$ reduction in body weight followed by maintenance. Participants in all groups except the LCD group were provided with all meals during baseline and for 12 weeks following randomization, and then were asked to self-select their food based on individually designed calorie targets. During weeks 22-24, they resumed the in-feeding diet. All diets (except the LCD) were based on recommendations per the American Heart Association (30\% fat) [56]. Participants in the LCD group consumed five shakes per day equaling $890 \mathrm{kcal} / \mathrm{d}$. Participants attended weekly group meetings and reported energy intake weekly by telephone. Skills to modify eating behavior and increase adherence to diet and exercise were taught using a cognitive-behavioral approach during group meetings. Participants in the CREX group engaged in a supervised, structured exercise program on three days per week. In addition, participants completed exercise on two additional days and used a heart rate monitor to track their efforts. During Baseline, Month 3, and Month 6 visits, participants attended a 5-day inpatient stay where numerous metabolic tests were conducted [55].

The key findings from Phase 1 of the CALERIE trial conducted at the Pennington Biomedical Research Center included the following measures: (1) percent weight change was significantly reduced among all participants, (2) all participants in diet groups had reductions in 24-h energy expenditure and 
DNA damage, (3) two biomarkers of longevity (fasting insulin and body temperature) were significantly reduced from baseline in the CR and CREX groups, and (4) DHEAS and glucose were unchanged from baseline across all groups [55]. Participants in the CR and CREX groups lost approximately $10 \%$ of their initial body weight, significantly reduced triacylglycerol, and increased HDL-cholesterol; thus their estimated 10-year cardiovascular disease risk [57] significantly declined from baseline by $29 \%$ in the CR group and $38 \%$ in the CREX group while remaining unchanged in the control group [58]. There was a significant decline in both fat and fat-free mass in both the CR and CREX groups. Visceral adipose tissue (VAT) and subcutaneous adipose tissue (SAT) were also significantly reduced from baseline in both CR and CREX groups, with no adverse changes in bone mineral density for total body or hip measures $[59,60]$. A significant increase in mean growth hormone (GH) and total insulin-like growth factor- 1 concentrations in the CREX and LCD groups [61], and a significant decrease in liver lipid content in the CR and LCD groups were also observed [62]. Moreover, participants in the CREX group showed a significant decrease in heart rate and sympathetic nervous system index, while demonstrating an increase in parasympathetic nervous system activity [63]. After six months of CR, mitochondrial DNA content increased by $35 \%$ in the CR group and $21 \%$ in the CREX group, but did not change in the control group, and DNA damage was reduced in both CR and CREX groups, but not in the control group [64].

At the Jean Mayer USDA Human Nutrition Research Center on Aging (HNRCA) at Tufts University, overweight $(25 \leq \mathrm{BMI}$ $<30 \mathrm{~kg} / \mathrm{m}^{2}$ ) but otherwise healthy adults (24-42 years old) participated in one year of CR. Participants were randomized to either $30 \% \mathrm{CR}$ or control group. Within each group, participants were also randomized to either a high glycemic load diet (i.e., mean estimated daily glycemic index of 86; HG) or low glycemic load diet (i.e., mean estimated daily glycemic index of 52; LG) based on the International Tables of Glycemic Index and Glycemic Load [64]. During the first phase (24 weeks) of the intervention, all food was prepared according to CR prescription and provided to the participants. During the second phase (24 weeks) of the intervention, participants were responsible for their own food preparation. To maximize adherence, participants attended weekly behavioral support groups and individual meetings with the study dietitian [65].

The key findings from Phase 1 of the CALERIE trial conducted at Tufts University revealed that participants in both intervention groups had significant weight loss, decrease in mean body fat percentage, and decrease in resting metabolic rate (RMR) from baseline [65]. Levels of triacylglycerol, insulin, as well as total, high-density lipoprotein (HDL), and lowdensity lipoprotein (LDL) cholesterol, decreased over time [65]. Participants with high insulin secretion at baseline lost more weight if randomized to the LG diet rather than the HG diet, compared to participants with low insulin secretion at baseline in the HG diet who lost more weight than those in the LG diet, but the difference was not statistically significant [66]. After six months of CR, activity of glutathione peroxidase (GPx) was increased, and markers of oxidative stress (i.e., plasma protein carbonyl and 8-Hydroxydeoxyguanosine) decreased. Changes in BMI, percent body fat, and fat mass were not found to be associated with changes in any of the markers of oxidative stress [67].

At the Washington University School of Medicine CALERIE site, healthy, non-obese (BMI range $=23.5$ $\left.29.9 \mathrm{~kg} / \mathrm{m}^{2}\right)$ men and postmenopausal women (50-60 years old) were randomly assigned to one of three groups: (1) the CR group; (2) the Exercise (EX) group; or (3) the Healthy Lifestyle (HL) group (control). The goal of the CR group was to gradually increase caloric restriction from $16 \%$ during the first three months to $20 \%$ during the remaining nine months of the intervention. Meals were provided for five consecutive days during both the $16 \% \mathrm{CR}$ and $20 \% \mathrm{CR}$ phases to help participants adjust to their prescription. Participants in the CR group attended weekly individual and/or group meetings for the first six months, then less frequently throughout the intervention. The goal of the EX group was to increase energy expenditure through exercise without changing caloric intake. Participants in the EX group gradually increased their energy expenditure from $16 \%$ to $20 \%$ and the intensity and frequency of exercise was personalized for each participant. Adherence was monitored by heart rate monitors and weekly weigh-in sessions throughout the intervention [68]. Based on double-labeled water measurement, participants achieved a mean CR of $11.5 \pm 2.1 \%$ after one year. Examination of food diaries revealed that energy intake decreased significantly in the first six months, but participants adhered less strictly during the final six months [68].

The key findings from Phase 1 of the CALERIE trial conducted at the Washington University School of Medicine for the CR and EX groups include (1) significant weight loss, (2) significant reductions in whole-body fat mass, (3) significant reductions in lean mass, and (4) significant decreases in VAT and SAT [69]. Additional analyses revealed a significant decrease in fasting insulin and insulin AUC, as well as an increase in insulin sensitivity index in the EX and CR groups, but not in the HL group. Serum adiponectin concentration tended to increase in the EX and CR groups and decreased significantly in the HL group; however, there were no differences between groups in fasting glucose or adjusted serum $\mathrm{TNF} \alpha$ concentrations [70]. Both interventions significantly reduced oxidative damage to DNA and RNA [12]. Overall, reductions in most of the major coronary heart disease risk factors, including plasma LDL-cholesterol, total cholesterol/ HDL ratio, and C-reactive protein concentrations were similar in both the CR and EX groups [71]. Physical fitness was improved in the EX group only as demonstrated by an increase in VO2max, compared to a decrease in the CR group [69]. 
Translation to Non-Overweight Individuals

A key issue for future research is whether or not the promising findings from initial CR trials in humans translate to humans who have a body mass index in the healthy range (i.e., BMI range $=20.0-24.9 \mathrm{~kg} / \mathrm{m}^{2}$ ). This question is currently being examined in Phase 2 of the CALERIE study, which utilized a multicenter, single-protocol focused on achieving and maintaining $25 \%$ calorie restriction in healthy, non-obese $\left(22.0 \leq \mathrm{BMI}<28.0 \mathrm{~kg} / \mathrm{m}^{2}\right)$ middle-aged men and women (21-50 years old) throughout a 2-year intervention period [72]. Specifically, Phase 2 of the CALERIE study is examining whether a $25 \%$ reduction in energy intake improves markers of aging, cardiovascular disease risk, insulin sensitivity and secretion, immune function, neuroendocrine function, quality of life, and cognitive function as compared to ad libitum intake. The results from this study will have important implications for our understanding of the impact of calorie restriction on biological changes associated with aging and age-related disease conditions [72].

\section{Long-Term Utility}

The promise of CR suggested by findings from the CALERIE study and other clinical trials only holds if individuals are able to maintain CR over the long term, as benefits are unlikely to remain present once individuals stop engaging in CR. Unfortunately, long-term compliance to dietary restriction regimens used in conventional weight loss programs is notoriously poor $[73,74]$. Two important biological compensatory mechanisms that increase the difficulty of sustaining CR are neuroendocrine signals and metabolic adaptation. During CR, anabolic output from neural pathways to increase food intake and simultaneously suppress energy expenditure are elevated. These neuroendocrine signals that occur during calorie restriction and following weight loss persist with prolonged weight reduction $[75,76]$. In addition, the reduction in total energy expenditure following weight loss is often greater than would be anticipated by the loss in lean body mass; a phenomenon termed metabolic adaptation. This phenomenon can lead to weight loss outcomes that are less than would be predicted by standard models [77].

Another major factor contributing to the difficulty of maintaining CR over the long term is our "toxic environment," where tasty high-fat, high-calorie foods are highly visible and easily available [78]. Exposure to an environment rich in palatable and calorie-dense foods can make sustained CR very challenging [78-80]. Complex interactions of physiological, psychosocial, and environmental factors can also increase the difficulty of maintaining CR over the long term. For example, following a period of restrictive dieting, people often experience a greater sensitivity to palatable food $[81,82]$.
Strategies to Promote Long-Term Adherence to CR

A variety of behavioral approaches have been tested to promote long-term adherence to reduced calorie diets in both the CALERIE trial as well previous weight loss interventions. In particular, long-term adherence has been found to be improved when participants receive continued contact with counselors and/ or other forms of positive social support [83]. Additionally, specific behavior skills including goal setting, self-monitoring, stimulus control, and problem solving have consistently been found to facilitate short-term and long-term adherence to reduced-calorie diets [83]. Specific dietary strategies, such as consumption of low-energy diets, have also been found to increase satiety levels and may be useful in promoting adherence to CR regimens [84]. The clinical utility of caloric restriction will likely be enhanced through continued testing of behavioral and dietary approaches to facilitate behavior change. Moreover, identification of pharmacological targets in the brain that may directly impact appetite control is needed. Thus, further study of the role that botanical compounds may have in facilitating appetite control is warranted in human clinical trials.

\section{Alternative Dietary Approaches}

An important area in need of further investigation is whether alternative dietary approaches, such as intermittent fasting, can produce biological changes and reductions in disease risk similar to caloric restriction [85•, 86, 87]. Findings from initial clinical trials suggest that this type of dietary approach has significant potential to improve markers of health in a manner that is independent of weight loss. A potential limitation of this type of dietary approach, however, is that it could lead to large quantities of food being consumed during non-fasting periods, which may produce adverse metabolic effects [88, 89]. Further research is needed to explore the potential risks/benefits associated with this type of eating pattern.

\section{Conclusions}

Caloric restriction has consistently been shown to delay the onset of age-related diseases and extend life span in numerous species including non-human primates. Findings from initial clinical trials in humans support the promise of CR suggested by pre-clinical studies to reduce disease risk and extend health-span. Unfortunately, long-term compliance to $\mathrm{CR}$ is notoriously poor and remains problematic. Although the specific reasons why long-term compliance to $\mathrm{CR}$ regimens is so difficult are not yet known, the complex interaction between physiological, psychological, behavioral, and environmental variables likely contribute to the challenge of maintaining CR over the long term. In response to diet-induced weight loss, internal feedback systems signal the body to increase food 
intake and decrease energy expenditure. These signals do not decrease over time and likely increase the difficulty of maintaining CR in an environment filled with readily available, highly palatable foods. Moreover, food-related sensory experiences, particularly sensitivity to palatable foods, appear to be enhanced following extended periods of $\mathrm{CR}$, which likely further contributes to the difficulty in maintaining $\mathrm{CR}$ over the long term. Given the multiple challenges that most individuals experience in sustaining $\mathrm{CR}$, research is needed to further explore novel behavioral, dietary, and biological interventions that can assist individuals in adhering to $\mathrm{CR}$ regimens. Additional areas of research that deserve attention are whether alternative dietary approaches, such as intermittent fasting, can produce similar beneficial effects as CR and whether this type of eating pattern may be maintained over the long term.

Acknowledgments Support was provided by the University of Florida Claude D. Pepper Older Americans Independence Center (NIH/NIA P30AG028740) and the Clinical and Translational Science Institute (NIH/NCRR UL1TR000064). Stephen Anton is supported by a K23 AT004251-01A2, an Early Career Investigator Award from the American Heart Association (09CRP2390173), and the Thomas H. Maren Foundation.

\section{Compliance with Ethics Guidelines}

Conflict of Interest Stephen D. Anton declares that he has no conflict of interest.

Christy Karabetian declares that she has no conflict of interest.

Kacey Heekin declares that she has no conflict of interest.

Christiaan Leeuwenburgh has received financial support through a grant from the University of Florida.

Human and Animal Rights and Informed Consent This article does not contain any studies with human or animal subjects performed by any of the authors.

\section{References}

Papers of particular interest, published recently, have been highlighted as:

- Of importance

1. Katz S, Branch LG, Branson MH, Papsidero JA, Beck JC, Greer DS. Active life expectancy. N Engl J Med. 1983;309:1218-24.

2. Branch LG, Jette AM. A prospective study of long-term care institutionalization among the aged. Am J Public Health. 1982;72:1373-9.

3. Colman RJ, Anderson RM, Johnson SC, Kastman EK, Kosmatka KJ, Beasley TM, et al. Caloric restriction delays disease onset and mortality in rhesus monkeys. Science. 2009;325:201-4.

4. Roth LW, Polotsky AJ. Can we live longer by eating less? A review of caloric restriction and longevity. Maturitas. 2012;71:315-9.

5. Chung HY, Cesari M, Anton S, Marzetti E, Giovannini S, Seo AY, et al. Molecular inflammation: underpinnings of aging and agerelated diseases. Ageing Res Rev. 2009;8:18-30.
6. Redman LM, Martin CK, Williamson DA, Ravussin E. Effect of caloric restriction in non-obese humans on physiological, psychological and behavioral outcomes. Physiol Behav. 2008;94:643-8.

7. Miller SL, Wolfe RR. The danger of weight loss in the elderly. J Nutr Health Aging. 2008;12:487-91.

8. Richardson A. The effect of age and nutrition on protein synthesis by cells and tissues from mammals. In: Watson RR (ed.), CRC handbook of nutrition in the aged. CRC Press; 1985: 31-48.

9. Watt DF. The biology of aging: Implications for understanding the diseases of aging and healthcare in the 21st century. In: Nari A, Sabbagh M (eds.), The Handbook of Geriatric Neurology. New York: FT Press; 2012.

10. Weindruch $\mathrm{R}$. The retardation of aging by caloric restriction: studies in rodents and primates. Toxicol Pathol. 1996;24:742-5.

11. Keys A. Caloric undernutrition and starvation, with notes on protein deficiency. J Am Med Assoc. 1948;138:500-11.

12. Hofer T, Fontana L, Anton SD, Weiss EP, Villareal D, Malayappan B, et al. Long-term effects of caloric restriction or exercise on DNA and RNA oxidation levels in white blood cells and urine in humans. Rejuvenation Res. 2008;11:793-9.

13. - Ivanova DG, Yankova TM. The free radical theory of aging in search of a strategy for increasing life span. Folia Med (Plovdiv ). 2013;55:33-41. This paper describes $C R$ as a mechanism for delaying the aging process due to its role in modifying the generation of free radicals, which are thought to contribute to the decline of physiological functions.

14. - Aris JP, Alvers AL, Ferraiuolo RA, Fishwick LK, Hanvivatpong A, $\mathrm{Hu} \mathrm{D}$, et al. Autophagy and leucine promote chronological longevity and respiration proficiency during calorie restriction in yeast. Exp Gerontol. 2013;48:1107-19. In yeast, CR enhances autophagy, which is a requirement in CR-mediated longevity. The availability of leucine during $C R$ also extends longevity and diminishes the requirement for autophagy.

15. Dutta D, Calvani R, Bernabei R, Leeuwenburgh C, Marzetti E. Contribution of impaired mitochondrial autophagy to cardiac aging: mechanisms and therapeutic opportunities. Circ Res. 2012;110: 1125-38.

16. Levine B, Klionsky DJ. Development by self-digestion: molecular mechanisms and biological functions of autophagy. Dev Cell. 2004;6:463-77.

17. Carames B, Taniguchi N, Otsuki S, Blanco FJ, Lotz M. Autophagy is a protective mechanism in normal cartilage, and its aging-related loss is linked with cell death and osteoarthritis. Arthritis Rheum. 2010;62: 791-801.

18. Zhang YB, Li SX, Chen XP, Yang L, Zhang YG, Liu R, et al. Autophagy is activated and might protect neurons from degeneration after traumatic brain injury. Neurosci Bull. 2008;24:143-9.

19. Selsby JT, Judge AR, Yimlamai T, Leeuwenburgh C, Dodd SL. Lifelong calorie restriction increases heat shock proteins and proteasome activity in soleus muscles of Fisher 344 rats. Exp Gerontol. 2005;40: 37-42.

20. Wohlgemuth SE, Julian D, Akin DE, Fried J, Toscano K, Leeuwenburgh C, et al. Autophagy in the heart and liver during normal aging and calorie restriction. Rejuvenation Res. 2007;10:281-92.

21. Civitarese AE, Carling S, Heilbronn LK, Hulver MH, Ukropcova B, Deutsch WA, et al. Calorie restriction increases muscle mitochondrial biogenesis in healthy humans. PLoS Med. 2007;4:e76.

22. Lagouge M, Argmann C, Gerhart-Hines Z, Meziane H, Lerin C, Daussin F, et al. Resveratrol improves mitochondrial function and protects against metabolic disease by activating SIRT1 and PGC1alpha. Cell. 2006;127:1109-22.

23. Weindruch R, Walford RL. Dietary restriction in mice beginning at 1 year of age: effect on life span and spontaneous cancer incidence. Science. 1982;215:1415-8.

24. Mair W, Dillin A. Aging and survival: the genetics of life span extension by dietary restriction. Annu Rev Biochem. 2008;77:727-54. 
25. - Fontana L, Partridge L, Longo VD. Extending healthy life spanfrom yeast to humans. Science. 2010;328:321-6. This paper describes how CR produces alterations in multiple connected nutrient signaling pathways in a manner that can extend life span in several organisms, including rodents.

26. Masoro EJ. Caloric restriction: a key to understanding and modulating aging. Elsevier Science; 2002.

27. Anderson RM, Shanmuganayagam D, Weindruch R. Caloric restriction and aging: studies in mice and monkeys. Toxicol Pathol. 2009;37:47-51.

28. Jiang JC, Jaruga E, Repnevskaya MV, Jazwinski SM. An intervention resembling caloric restriction prolongs life span and retards aging in yeast. FASEB J. 2000;14:2135-7.

29. Lin SJ, Kaeberlein M, Andalis AA, Sturtz LA, Defossez PA, Culotta VC, et al. Calorie restriction extends Saccharomyces cerevisiae life span by increasing respiration. Nature. 2002;418:344-8.

30. Lin SJ, Defossez PA, Guarente L. Requirement of NAD and SIR2 for life span extension by calorie restriction in Saccharomyces cerevisiae. Science. 2000;289:2126-8.

31. Kaeberlein M, Kirkland KT, Fields S, Kennedy BK. Sir2independent life span extension by calorie restriction in yeast. PLoS Biol. 2004;2:E296.

32. Kaeberlein M, Powers III RW, Steffen KK, Westman EA, Hu D, Dang N, et al. Regulation of yeast replicative life span by TOR and Sch9 in response to nutrients. Science. 2005;310:1193-6.

33. Partridge L, Piper MD, Mair W. Dietary restriction in Drosophila. Mech Ageing Dev. 2005;126:938-50.

34. Grandison RC, Piper MD, Partridge L. Amino-acid imbalance explains extension of life span by dietary restriction in Drosophila. Nature. 2009;462:1061-4.

35. Burger JM, Buechel SD, Kawecki TJ. Dietary restriction affects life span but not cognitive aging in Drosophila melanogaster. Aging Cell. 2010;9:327-35.

36. Lynch M, Ennis R. Resource availability, maternal effects, and longevity. Exp Gerontol. 1983;18:147-65.

37. Klass MR. Aging in the nematode Caenorhabditis elegans: major biological and environmental factors influencing life span. Mech Ageing Dev. 1977;6:413-29.

38. Vanfleteren JR, Braeckman BP. Mechanisms of life span determination in Caenorhabditis elegans. Neurobiol Aging. 1999;20:487-502.

39. Houthoofd K, Braeckman BP, Lenaerts I, Brys K, De VA, Van ES, et al. Axenic growth up-regulates mass-specific metabolic rate, stress resistance, and extends life span in Caenorhabditis elegans. Exp Gerontol. 2002;37:1371-8.

40. Kaeberlein TL, Smith ED, Tsuchiya M, Welton KL, Thomas JH, Fields S, et al. Life span extension in Caenorhabditis elegans by complete removal of food. Aging Cell. 2006;5:487-94.

41. Kirk KL. Dietary restriction and aging: comparative tests of evolutionary hypotheses. J Gerontol A Biol Sci Med Sci. 2001;56:B123-9.

42. Gribble KE, Welch DB. Life span extension by caloric restriction is determined by type and level of food reduction and by reproductive mode in Brachionus manjavacas (Rotifera). J Gerontol A Biol Sci Med Sci. 2013;68:349-58.

43. Austad SN. Life extension by dietary restriction in the bowl and doily spider, Frontinella pyramitela. Exp Gerontol. 1989;24:83-92.

44. Terzibasi E, Lefrancois C, Domenici P, Hartmann N, Graf M, Cellerino A. Effects of dietary restriction on mortality and agerelated phenotypes in the short-lived fish Nothobranchius furzeri. Aging Cell. 2009;8:88-99.

45. Stuchlikova E, Juricova-Horakova M, Deyl Z. New aspects of the dietary effect of life prolongation in rodents. What is the role of obesity in aging? Exp Gerontol. 1975;10:141-4.

46. Kealy RD, Lawler DF, Ballam JM, Mantz SL, Biery DN, Greeley $\mathrm{EH}$, et al. Effects of diet restriction on life span and age-related changes in dogs. J Am Vet Med Assoc. 2002;220:1315-20.
47. Lawler DF, Larson BT, Ballam JM, Smith GK, Biery DN, Evans RH, et al. Diet restriction and ageing in the dog: major observations over two decades. Br J Nutr. 2008;99:793-805.

48. Weindruch R, Walford RL. The retardation of aging and disease by dietary restriction. Charles C. Thomas Publisher, Limited; 1988.

49. Ingram DK, de CR, Anson RM, Ottinger MA, Lane MA, Roth GS, Mattison JA. Calorie restriction in nonhuman primates: Impact on aging, disease, and frailty. In: Carey JR, Robine JM, Michel JP (eds.), Longevity and Frailty. Springer; 2006: 39-56.

50. • Mattison JA, Roth GS, Beasley TM, Tilmont EM, Handy AM, Herbert $\mathrm{RL}$, et al. Impact of caloric restriction on health and survival in rhesus monkeys from the NIA study. Nature. 2012;489:318-21. CR in young and older-age rhesus monkeys did not improve survival outcomes; thus, outcomes in terms of health effects, morbidity, and mortality should be examined independent of the effects of CR on survival.

51. Kemnitz JW. Calorie restriction and aging in nonhuman primates. ILAR J. 2011;52:66-77.

52. Lane MA, Black A, Handy A, Tilmont EM, Ingram DK, Roth GS. Caloric restriction in primates. Ann N Y Acad Sci. 2001;928:287-95.

53. Lane MA, Ingram DK, Ball SS, Roth GS. Dehydroepiandrosterone sulfate: a biomarker of primate aging slowed by calorie restriction. $\mathrm{J}$ Clin Endocrinol Metab. 1997;82:2093-6.

54. Roth GS, Lesnikov V, Lesnikov M, Ingram DK, Lane MA. Dietary caloric restriction prevents the age-related decline in plasma melatonin levels of rhesus monkeys. J Clin Endocrinol Metab. 2001;86: 3292-5.

55. Heilbronn LK, de Jonge L, Frisard MI, DeLany JP, Larson-Meyer DE, Rood J, et al. Effect of 6-month calorie restriction on biomarkers of longevity, metabolic adaptation, and oxidative stress in overweight individuals: a randomized controlled trial. JAMA. 2006;295:1539-48.

56. Krauss RM, Deckelbaum RJ, Ernst N, Fisher E, Howard BV, Knopp $\mathrm{RH}$, et al. Dietary guidelines for healthy American adults. A statement for health professionals from the Nutrition Committee, American Heart Association. Circulation. 1996;94:1795-800.

57. Anderson KM, Wilson PW, Odell PM, Kannel WB. An updated coronary risk profile. A statement for health professionals. Circulation. 1991;83:356-62.

58. Lefevre M, Redman LM, Heilbronn LK, Smith JV, Martin CK, Rood $\mathrm{JC}$, et al. Caloric restriction alone and with exercise improves CVD risk in healthy non-obese individuals. Atherosclerosis. 2009;203: 206-13.

59. Redman LM, Heilbronn LK, Martin CK, Alfonso A, Smith SR, Ravussin E. Effect of calorie restriction with or without exercise on body composition and fat distribution. J Clin Endocrinol Metab. 2007;92:865-72.

60. Redman LM, Rood J, Anton SD, Champagne C, Smith SR, Ravussin E. Calorie restriction and bone health in young, overweight individuals. Arch Intern Med. 2008;168:1859-66.

61. Redman LM, Veldhuis JD, Rood J, Smith SR, Williamson D, Ravussin E. The effect of caloric restriction interventions on growth hormone secretion in nonobese men and women. Aging Cell. 2010;9:32-9.

62. Larson-Meyer DE, Newcomer BR, Heilbronn LK, Volaufova J, Smith SR, Alfonso AJ, et al. Effect of 6-month calorie restriction and exercise on serum and liver lipids and markers of liver function. Obesity (Silver Spring). 2008;16:1355-62.

63. de Jonge L, Moreira EA, Martin CK, Ravussin E. Impact of 6-month caloric restriction on autonomic nervous system activity in healthy, overweight, individuals. Obesity (Silver Spring). 2010;18:414-6.

64. Foster-Powell K, Holt SH, Brand-Miller JC. International table of glycemic index and glycemic load values: 2002. Am J Clin Nutr. 2002; 76:5-56.

65. Das SK, Gilhooly CH, Golden JK, Pittas AG, Fuss PJ, Cheatham RA, et al. Long-term effects of two energy-restricted diets differing in glycemic load on dietary adherence, body composition, and 
metabolism in CALERIE: a 1-y randomized controlled trial. Am J Clin Nutr. 2007;85:1023-30.

66. Pittas AG, Das SK, Hajduk CL, Golden J, Saltzman E, Stark PC, et al. A low-glycemic load diet facilitates greater weight loss in overweight adults with high insulin secretion but not in overweight adults with low insulin secretion in the CALERIE Trial. Diabetes Care. 2005;28:2939-41.

67. Meydani M, Das S, Band M, Epstein S, Roberts S. The effect of caloric restriction and glycemic load on measures of oxidative stress and antioxidants in humans: results from the CALERIE Trial of Human Caloric Restriction. J Nutr Health Aging. 2011;15:456-60.

68. Racette SB, Weiss EP, Villareal DT, Arif H, Steger-May K, Schechtman KB, et al. One year of caloric restriction in humans: feasibility and effects on body composition and abdominal adipose tissue. J Gerontol A Biol Sci Med Sci. 2006;61:943-50.

69. Weiss EP, Racette SB, Villareal DT, Fontana L, Steger-May K, Schechtman KB, et al. Lower extremity muscle size and strength and aerobic capacity decrease with caloric restriction but not with exercise-induced weight loss. J Appl Physiol. 2007;102:634-40.

70. Weiss EP, Racette SB, Villareal DT, Fontana L, Steger-May K, Schechtman KB, et al. Improvements in glucose tolerance and insulin action induced by increasing energy expenditure or decreasing energy intake: a randomized controlled trial. Am J Clin Nutr. 2006;84: $1033-42$.

71. Fontana L, Villareal DT, Weiss EP, Racette SB, Steger-May K, Klein $\mathrm{S}$, et al. Calorie restriction or exercise: effects on coronary heart disease risk factors. A randomized, controlled trial. Am J Physiol Endocrinol Metab. 2007;293:E197-202.

72. Rochon J, Bales CW, Ravussin E, Redman LM, Holloszy JO, Racette $\mathrm{SB}$, et al. Design and conduct of the CALERIE study: comprehensive assessment of the long-term effects of reducing intake of energy. $\mathrm{J}$ Gerontol A Biol Sci Med Sci. 2011;66:97-108.

73. Scheen AJ. Management of the metabolic syndrome. Minerva Endocrinol. 2004;29:31-45.

74. Scheen AJ. The future of obesity: new drugs versus lifestyle interventions. Expert Opin Investig Drugs. 2008;17:263-7.

75. MacLean PS, Higgins JA, Jackman MR, Johnson GC, Fleming-Elder BK, Wyatt HR, et al. Peripheral metabolic responses to prolonged weight reduction that promote rapid, efficient regain in obesity-prone rats. Am J Physiol Regul Integr Comp Physiol. 2006;290:R1577-88.
76. Sumithran P, Prendergast LA, Delbridge E, Purcell K, Shulkes A, Kriketos A, et al. Long-term persistence of hormonal adaptations to weight loss. N Engl J Med. 2011;365:1597-604.

77. Wishnofsky M. Caloric equivalents of gained or lost weight. Am J Clin Nutr. 1958;6:542-6.

78. Hill JO, Peters JC. Environmental contributions to the obesity epidemic. Science. 1998;280:1371-4.

79. Poston WS, Foreyt JP. Obesity is an environmental issue. Atherosclerosis. 1999;146:201-9.

80. Hill JO, Wyatt HR, Reed GW, Peters JC. Obesity and the environment: where do we go from here? Science. 2003;299:853-5.

81. Zverev YP. Effects of caloric deprivation and satiety on sensitivity of the gustatory system. BMC Neurosci. 2004;5:5.

82. Rodin J, Schank D, Striegel-Moore R. Psychological features of obesity. Med Clin N Am. 1989;73:47-66.

83. Middleton KR, Anton SD, Perri MG. Long-term adherence to health behavior change. Am J Lifestyle Med. 2013. In Press

84. Rolls BJ, Bell EA. Dietary approaches to the treatment of obesity. Med Clin N Am. 2000;84:401-18. vi.

85. - Arguin H, Dionne IJ, Senechal M, Bouchard DR, Carpentier AC, Ardilouze JL, et al. Short- and long-term effects of continuous versus intermittent restrictive diet approaches on body composition and the metabolic profile in overweight and obese postmenopausal women: a pilot study. Menopause. 2012;19:870-6. Intermittent restrictive dieting was as effective as a continuous energy restricted diet for both short-term and long-term changes in body composition and metabolic improvements.

86. Katare RG, Kakinuma Y, Arikawa M, Yamasaki F, Sato T. Chronic intermittent fasting improves the survival following large myocardial ischemia by activation of BDNF/VEGF/PI3K signaling pathway. $\mathrm{J}$ Mol Cell Cardiol. 2009;46:405-12.

87. Lee C, Longo VD. Fasting vs dietary restriction in cellular protection and cancer treatment: from model organisms to patients. Oncogene. 2011;30:3305-16.

88. Ceriello A. Postprandial hyperglycemia and diabetes complications: is it time to treat? Diabetes. 2005;54:1-7.

89. Devaraj S, Wang-Polagruto J, Polagruto J, Keen CL, Jialal I. Highfat, energy-dense, fast-food-style breakfast results in an increase in oxidative stress in metabolic syndrome. Metabolism. 2008;57:86770. 